\title{
A New Approach in Event Studies: Time Varied Analysis
}

\author{
Yi $\operatorname{Ren}^{1} \&$ Dong Xiao ${ }^{2}$ \\ ${ }^{1}$ Department of Accounting, Illinois State University, Normal, IL, USA \\ ${ }^{2}$ Department of Statistics, North Carolina State University, Raleigh, NC, USA \\ Correspondence: Yi Ren, PhD, Department of Accounting, Illinois State University, USA
}

Received: July 12, 2019

Accepted: August 13, 2019

Online Published: August 19, 2019

doi:10.5430/afr.v8n3p176

URL: https://doi.org/10.5430/afr.v8n3p176

\begin{abstract}
This study proposes a modified market model of event study that takes into account the asynchronous behavior between individual stocks and the stock market by using an added Chebyshev polynomial term. The proposed model takes into account both the macro market performance and the micro individual stock behavior and is empirically tested. The empirical analysis results demonstrate that the proposed model improves the explanatory power of the model as well as the heteroskedasticity. More importantly, its performance is almost independent of the choice of the events and stocks.
\end{abstract}

Keywords: event studies, time-related market model, Chebyshev polynomials

\section{Introduction}

Since the publication of two papers by Ball and Brown (1968) and Fama et al. (1969), event studies have become very popular in accounting and finance research. As noted by Kothari and Warner (2007), a number of event studies have been published and the literature continues to grow. The majority of event studies are focused on estimations of the impacts of unanticipated events on stock prices. The studies include stock reactions to stock splits (e.g., Fama, Fisher, Jensen and Roll, 1969; Grinblatt, Masulis, and Titman, 1984; McNichols and Dravid, 1990; Louis and Robinson, 2005; Baker et al, 2009), effects of earnings announcements and dividends (e.g., Foster, Olsen, and Shevlin, 1984; Brown and Warner, 1985; MacKinlay, 1997), investigations of merger and acquisition events (e.g., Eckbo, 1983; Jarrell and Poulsen, 1989; Kothari and warner, 2007) and public security offering announcements (e.g., Mikkelson and Partch, 1986; Barclay and Litzenberger, 1988; Ritter, 1991), etc. Moreover, event studies are also widely applied in other related business fields. For example, the Securities and Exchange Commission (SEC) applied the event study in its enforcement actions on security fraud cases (see Mitchell and Netter, 1994). Also event studies are used to measure the effects of regulation (see Schwert, 1981; also see Bhagat and Romano 2002a and 2002b for the discussion and review of event studies of regulation). In the marketing field, Agrawal and Kamakura (1995) uses the event study to examine the economic worth of celebrity endorsers.

The event study methodology has evolved since its emergence. A number of modifications have been developed to address violations of statistical assumptions used in the early work and to accommodate more specific hypotheses (MacKinlay, 1997). There are several potential problems with hypothesis testing due to the dependencies in the residuals, heteroskedasticity (unequal variance of residuals), and autocorrelation (residuals are correlated). Collins and Dent (1984) and Bemard (1987) find that unequal variances across firms and cross-sectional dependence introduce considerable bias on hypothesis testing in event studies. A common modification to address the problem with dependencies in residuals is to standardize each abnormal return using an estimator of its standard deviation (i.e., Jaffe, 1974; Mandelker, 1974; Patell, 1976; Dodd and Warner, 1983). There is a stream of studies that address the issues of event-induced heteroskedasticity and the correlation in residuals, and provide technical approaches (White, 1980; Collins and Dent, 1984; Malatesta and Thompson, 1985; Froot, 1989; Boehmer et al., 1991; Cowan, 1991; Sweeney, 1991; Salinger, 1992).

In this study, we discuss the methodology of measuring security reaction to event, in terms of assumptions, requirements and limitations of the event study. Further, we propose a new improvement to the event study methodology. Our proposed model improves its explanatory power as well as the heteroskedasticity. More importantly, its performance is almost independent of the choice of the events and stocks. This paper begins with a discussion of the structure of the event study and its methodological development. In section 2, we discuss the assumptions and requirements of event study methodology and address potential issues. In section 3, using an 
example, we evaluate the market model. In section 4, we propose a time-related market model with an added Chebyshev polynomial term. In section 5, we empirically examine the modified model with layoff events from 1997 to 2006. The improvement is best presented in Figure 1. Section 6 summarizes and concludes the study.

\section{Event Study Methodology}

The most influential pioneer event studies were by Fama, Fisher, Jensen and Roll (FFJR) (1969) and Ball and Brown (1968). FFJR studied how the market reacted to announcements of stock splits, and Ball and Brown considered the information content of accounting earnings. Both studies introduced the methodology of event study that is essentially the same as that which is in use today (Mackinlay, 1997). The fundamental use of an event study is to investigate the effect of an event on stock prices. The event effect is measured by utilizing statistical models. The goal of the event study is to examine the difference between the observed stock return and the expected return under a hypothetical situation - without the event taking place. Then statistical tests are used to determine whether the observed effect of the event is significant. If statistical significance can be found, then it suggests that the event has a significant effect on the stock. Otherwise, it may imply that the event has no significant impact.

A typical event study involves two time periods: event window and estimation window. The event window is the time period that the event is supposed to have the most impact on the subject. The estimation window is the time period used to estimate the stock assuming no event taking place and is thus earlier than the event window. In the literature the event window and the estimation window may or may not be adjacent to each other. So there may be an interval window that is between the event window and the estimation window.

The key step of the event study is to estimate the stock movement assuming no event taking place. Various methods have been used to model the stock behavior. Among them the constant mean model is the most straightforward. In this method, the average value within the estimation window is used as estimation in the event window. Although the constant mean method is perhaps the simplest model, sometimes it may yield similar performance or even outperform the more complicated methodologies (Brown and Warner, 1980, 1985). While the constant mean model may work well for some cases, the feasibility is reduced sharply when the examined subject is closely related to additional factors. Thus the market model such as equation (1) is proposed to include the effect of the overall market.

$$
R_{i t}=\alpha_{i}+\beta_{i} \times R_{M t}+u_{i t}
$$

where $R_{i t}$ and $R_{M t}$ denote the stock return for firmi and the market return on day t. The market model relates the return of any given security to the return of the market portfolio (Mackinlay, 1997). The market model represents a potential improvement over the constant mean model since the model includes the influence of the overall market on the firm's stock. However, this is not always true. Brown and Warner (1980) present evidence that more complicated methodologies can actually make research worse off compared to simpler methods like mean adjusted return.

A number of other statistical models have been proposed to address additional factors that may influence the measure of the normal return. The use of the Capital Asset Pricing Model (CAPM) (proposed by Sharpe, 1964 and Lintner, 1965) or the Black Asset Price Model (Black, 1972) in event studies is normally referred to as the market and risk adjusted return model (Brown and Warner, 1980). With the added term of risk-free return, the modified model includes the effect of risk into the basic market model. However, Fama and French (1996) questioned the validity of the imposed condition on the market model. Other models have been proposed motivated by the Arbitrage Pricing theory (APT) (proposed by Ross in 1976). However, the gains from these models versus the market model are not conclusive (Brown and Weinstein 1985). Furthermore, multifactor models have been introduced to increase the explanatory power of the model, such as the three-factor model developed by Fama and French (1993) and the four factor model developed by Carhart (1997). In addition, some researchers have proposed to use a portfolio instead of the overall market as an alternative to the market model (e.g., Barber and Lyon, 1997; Fama, 1998; Eckbo, et al., 2000; or Mitchell and Stafford, 2000). The method may produce higher power of test statistics than the overall market highly depending on the selection of firms with similar characteristics.

There are two essential assumptions in the event study. First, the event is known to the public only upon the event date. If the event is revealed or well expected before the announcement of the event, then the event study may not fully detect the impact of the event (Glascock, et al., 1987). For example, using the event study to examine the effect of a Fed interest rate hike on the market, one will not find accurate results about the effect because the market may have already expected its occurrence before the Fed's decision based on the economic trend and job market data etc. Thus, the market may change the expectation of the interest rate hike when the job report is announced. This is exactly what happened when healthy hiring data was announced on March 6, 2015. The S\&P 500 index dropped 1.42\% that day following the news release. However, the announcement of an interest rate hike may still impact the market 
because there is a difference between the expectation and the outcome. The event study of the Fed interest rate hike announcement may suggest the impact of the announcement on the market instead of the impact of the interest rate hike. Perhaps we could interpret the results as the difference between the market expectation and the impact of the hike in interest rate.

Secondly, the outcome in the event window under the presumption of no-event occurrence is predictable by its behavior in the estimation window. This is a very crucial assumption in the event study. For example, if the outcome is totally random and does not depend on its past behavior, then there is no scientific way to predict the expected value in the event window. In the case of the market model, we further assume that the stock is synchronous with the market. The market model is time independent because its coefficients are not dependent on time. The market model infers that the time dependence of the stock return is assumed to be the same as that of the overall market.

In reality, however, this assumption sometimes does not hold since traders make decisions asynchronously (Boer et al., 2006). Although the market model works well when the stock returns are synchronous with the overall market, the same model may not give satisfactory results when the stock returns are not well correlated with overall market returns.

In addition to the two assumptions discussed above, the event study also requires the following conditions to be satisfied: First, no significant events other than the investigated event exist in the event window. We need to avoid other events that may trigger stock changes, especially the event that cannot be captured by the overall market. If other events are included in the event window, the difference in the observed and the estimated return may include the influences of both investigated and unwanted events. This requirement is also extended to the estimation window. If other events are included in the estimation window, the effect of unwanted events will be imposed into the event window. However, it is sometimes unrealistic to eliminate other events in the estimation window because of its long time period. Since the long-horizon of the estimation window may decrease the influences of the unwanted events, the extension into the estimation window may be treated as an optimization instead of a requirement.

The Second requirement is that the length of the estimation window should be much longer than the length of the event window. Mathematically, the procedure of extending the model developed inside the estimation window into the event window is called extrapolation. The quality of extrapolation is largely determined by the function form (i.e., the model) and the extrapolation range. The extrapolation range could be a major concern in the event study. First, a large event window may increase the possibility of inclusion of other unwanted events. More importantly, extrapolation as a mathematical numeric technique may go "berserk" if the extrapolation range is too large (Press et al., 4th edition, p101). Previous research has already pointed out the ineffectiveness and limitation of using long-horizon event windows (i.e., Brown and Warner, 1985; Kothari and Warner, 1997; Lyon et al., 1999; Bessembinder et al., 2009). Thus, we suggest limiting the use of the event study in long-horizon event window and minimizing the interval between the estimation window and the event window as well. Furthermore, there may be some nuances of corporate governances may trigger major differences in outcomes (i.e., Core and Guay, 1999; Giroud and Mueller, 2011; Li, 2014).

The assumptions and requirements suggest that the event study has its limitations in some cases. As illustrated in the Chaos Theory, a small perturbation in the initial condition (i.e., a seemingly unrelated event) may trigger a large outcome change in a later state (i.e., a change in stock return) known "the butterfly effect." It infers that sometimes it is impossible to exclude the impact of the unwanted events.

\section{Results}

\subsection{Evaluation of the Market Model}

As we have discussed in the above, the market model works well when the firm's stock return is highly synchronized with the overall market return. However, the performance of a security is also related to many other factors such as industry trends, the firm's accounting performance etc. Thus it is not unusual to see some securities perform very differently from the overall market. In this case the market model may not work very well and the regression model may only explain a small portion of $R_{i t}$ and leave the remaining unexplained part to the stochastic error $u_{i t}$.

As we know, the efficiency of the model is determined by its explanatory power. The coefficient of determination $\mathrm{r} 2$ is an indicator of the model efficiency and we apply $\mathrm{r} 2$ of the market model in the estimation window to examine its efficiency. The indicator $\mathrm{r} 2$ may tell us how efficient the model is when we use it to predict the later returns in the event window, which is the second step and not necessary to include as of now. Here we use the market model to regress the daily stock return of the Apple Inc. (AAPL), General Electric (GE) and Wal-Mart Stores Inc. (WMT) in the estimation window of the year 2010. The securities are chosen based on their popularity while the time window is 
picked rather randomly. We use S\&P 500 as the market measure since all three companies are components of S\&P 500. Table 1 presents the results based on the basic market model as shown in equation (1). The results illustrate that although all three stocks are significantly associated with S\&P 500 as expected, the coefficients of determination $\mathrm{r} 2$ are quite different. For example, the model is able to explain $68 \%$ of GE's returns, but the same model can only explain $25 \%$ of WMT's returns in the same year. It suggests that in 2010 GE's return is more synchronized with the market return, while WMT's return behaves very differently from S\&P 500 returns.

Table 1. Results of Market Model on Stocks of AAPL, GE and WMT in 2010

\begin{tabular}{cccc}
\hline & $A A P L$ & $G E$ & $W M T$ \\
\hline $\mathrm{N}$ (days of estimation window) & 252 & 252 & 252 \\
Mean & 0.1832 & 0.101 & 0.0164 \\
constant & $0.126^{*}$ & 0.0332 & -0.0046 \\
& $(1.68)$ & $(0.54)$ & $(-0.1)$ \\
RM (Market Return) & $1.053^{* * *}$ & $1.251^{* * *}$ & $0.388^{* * *}$ \\
& $(15.94)$ & $(22.97)$ & $(9.16)$ \\
r2 (Fitness) & 0.504 & 0.679 & 0.251 \\
\hline
\end{tabular}

\subsection{Time-related Market Model}

The results shown in Table 1 illustrate the limitation of the market model. Although it is a useful macro model in the event study, the model does not show the firm-level dependence. In a large sample that is composed of many firm stocks, it is almost impossible to synchronize all firms to the overall market or a specified portfolio. That's why sometimes it is not much better than the constant mean model. Here we propose an improvement of the market model by incorporating the different firm-level behavior in the model.

The market model is a time independent model with constant coefficients $\alpha_{i}$ and $\beta_{i}$ except the market return $R_{M t}$, which is time dependent. The model works well only when the individual stocks are synchronous with the overall market. The influence of the asynchronous trading effect on the individual stocks is also discussed by MacKinlay (1997). Here we increase the explanatory power of the market model by adding a time-dependent term to address the different firm-level time-related effects.

Inspired by Taylor's Theorem, here we use a polynomial, the extra time-dependent term. The Theorem states that any well-behaved smooth function can be accurately described by a polynomial provided that the spacing is small. Polynomials are the simplest functions that have the flexibility to represent general nonlinear relationships. It is well perceived that the curve of the stock return may have sharp peaks and valleys within a short time period (i.e., several time steps). Because stock returns are more volatile than stock prices, it is very difficult to find appropriate smooth function forms to capture the behavior of stock returns. So instead we use stock price in the regression model. It is possibly true that $\operatorname{Ln} P_{i t}$ and $\operatorname{Ln} M P_{t}$ are not stationary. But from a mathematical point of view, the stock return is the first derivative of stock price. If the stock price is not stationary, then there is no mathematical proof that the stock return will be stationary. We do not think the use of stock price, instead of stock return, may exacerbate the non-stationary properties compared with the basic market model.

However, the simple form of the polynomial has one disadvantage: all the terms in the polynomial are highly correlated. If we treat the polynomial regression as a multiple regression model, multicollinearity among the variables will severely limit the accuracy of the model. The model may become ill-conditioned and any small variations in the input, including the rounding error, will be magnified and cause large changes in the results. So we use the orthogonal polynomials to ensure the terms are orthogonal to each other. Here is the proposed time-related market model:

$$
\ln P_{i t}=\alpha_{i}+\beta_{i} \times \ln P_{M t}+\sum_{k=1}^{n} \gamma_{i k} \times T_{k}(t)+\epsilon_{i t}
$$

With the Chebyshev polynomials (Arfken and Weber, 1995, p786), we have

$$
\begin{aligned}
& T_{0}(t)=1 \\
& T_{1}(t)=t \\
& T_{2}(t)=2 t^{2}-1 \\
& \vdots \\
& T_{k}(t)=2 t T_{k-1}(t)-T_{k-2}(t)
\end{aligned}
$$


where $P_{i t}$ is the stock closing price of firm i at day t and $P_{M t}$ is the market closing price at day $\mathrm{t} . \mathrm{n}$ is the highest order of the polynomial. With the use of the Chebyshev polynomials, we satisfy the orthogonality condition. The condition guarantees that all orthogonal polynomial terms are not correlated to each other. All price variables are regressed using their natural logarithm forms due to elasticity. Variable $t$ ranges from 0 to 1 in the estimation window so that two ends of the estimation window have analytic expressions and do not depend on the number of trading days in the estimation window. Thus the number of trading days will determine the step size of the estimation window. For example, if we have 250 trading days in the estimation window, then the step size is 0.004 . The accuracy of the model increases with the order of the polynomial n. However there is a trade-off with the use of high-order polynomials: the extrapolation range may decrease with the larger $\mathrm{n}$ for a specified accuracy of extrapolation.

It is worthwhile to compare the error term of model (2) with that of model (1). We simplify the dependent variable $\ln P_{t}$ into two components: the explained term $\ln E P_{t}$ and the error term $\delta_{t} \ln P_{t}$ :

$$
\ln P_{t}=\ln E P_{t}+\delta_{t} \ln P_{t}
$$

where $E P_{t}$ denotes the part of the stock price that may be explained by the modified model and $\delta_{t}=\frac{\epsilon_{t}}{\ln P_{t}}$ is the percentage of the error term in the stock price. Use the exponential function on both sides of equation (4), we have

$$
P_{t}=E P_{t}^{1 /\left(1-\delta_{t}\right)}
$$

and the return on the stock can be calculated as follows:

$$
\begin{aligned}
R_{t} & =\frac{P_{t}-P_{t-1}}{P_{t-1}} \\
& =\frac{E P_{t}^{1 /\left(1-\delta_{t}\right)}-E P_{i-1}{ }^{1 /\left(1-\delta_{t-1}\right)}}{P_{t-1}}
\end{aligned}
$$

We may expand $E P_{t}{ }^{1 /\left(1-\delta_{t}\right)}$ and $E P_{i-1}{ }^{1 /\left(1-\delta_{t-1}\right)}$ in Taylor Series, then

$$
\begin{aligned}
R_{t} & =\frac{E P_{t}+\delta_{t}+O\left(\delta_{t}^{2}\right)-\left[E P_{t-1}+\delta_{t-1}+O\left(\delta_{t-1}^{2}\right)\right]}{P_{t-1}} \\
& =\frac{E P_{t}-E P_{t-1}}{P_{t-1}}+\frac{\left(\delta_{t}-\delta_{t-1}\right)+\left[O\left(\delta_{t}^{2}\right)-O\left(\delta_{t-1}^{2}\right)\right]}{P_{t-1}}
\end{aligned}
$$

where Os indicate error terms in the order of $\delta_{\mathrm{t}}^{2}$. Since the ratio of the error term to the stock price $\delta_{\mathrm{t}}$ is much smaller than 1, $\mathrm{O}$ terms can be neglected and thus the explained return (part of the return that can be explained by the model) $E R_{t}=\frac{E P_{t}-E P_{t-1}}{E P_{t-1}}$ approximately equals to $\frac{E P_{t}-E P_{t-1}}{P_{t-1}}$. Then we have

$$
R_{t}=E R_{t}+\Delta R_{t}=\frac{E P_{t}-E P_{t-1}}{P_{t-1}}+\frac{\delta_{t}-\delta_{t-1}}{P_{t}-P_{t-1}} R_{t}
$$

The term $\frac{\delta_{t}-\delta_{t-1}}{P_{t}-P_{t-1}} R_{t}$ approximately corresponds to the error term that cannot be explained by the model. Thus the use of stock price, instead of stock return, in the market model may produce an error $\frac{\delta_{t}-\delta_{t-1}}{P_{t}-P_{t-1}} R_{t}$. Obviously, the $\Delta$ will be very small as long as $\delta_{t}$ is not highly dependent on time. In the appendix we also show the transformation of the market model with the stock price as the variable to the market model with the stock return as the variable. It turns out that the market model with the stock price as the variable and without the polynomial term $(\mathrm{n}=0)$ may transform to a market model with the stock return as the variable.

Now we use the same example used in Table 1 to show the benefit of the modified market model as in Equation (2). Table 2 reports the regression results for the example when the polynomial order $\mathrm{n}$ takes value of 0,3 , and 5 . The case of $n=0$ corresponds to the model without the Chebyshev polynomial term, which is the market model with the stock price as the variables. It can be used as the reference to show the explanatory power of the time-related terms.

In Table 2, we find that the inclusion of the time-dependent polynomials offers an improved $\mathrm{r} 2$ for all three stocks compared to the basic market model (in Table 1) and the $\mathrm{n}=0$ case (in Table 2). The inclusion of the time-dependent polynomial significantly increases the explanatory power of the model especially when the market model fails to give a reasonable explanatory power. The modified time-dependent market model takes into account both the macro market-related factor and the time dependence of the individual firm. As showing in Table 2, while a polynomial of order 3 is normally enough for the regression model, a polynomial of order 5 may give meaningfully better results in some cases. On the other hand we do not recommend polynomials of much higher order because it may dramatically 
decrease the extrapolation range of the event window as we discussed earlier.

If we compare the results from Table 1 and Table 2, we find that $\mathrm{r} 2$ of the market model on the three stocks are 0.5 , 0.7 , and 0.25 , respectively. In Table $2, \mathrm{r} 2$ under our proposed model when $\mathrm{n}=0$ (without the Chebyshev polynomial term) are $0.3,0.6$, and 0.7. It is clear that improvement of $\mathrm{r} 2$ mainly happens when we increase the polynomial order since it offers more accurate prediction in the event window. Also, $\mathrm{r} 2$ is a universal measure of model's explanatory power and may indicate how fit the models are. Since it is actually a ratio of the explained variation to the total variation, $\mathrm{r} 2$ can be used to compare two models with different variables such as compare model (1) and (2) as in our paper.

Table 2. Proposed Time-Varied Market Model Results on Three Stocks AAPL, GE and WMT in 2010

\begin{tabular}{|c|c|c|c|c|c|c|c|c|c|}
\hline & \multicolumn{3}{|c|}{$A A P L$} & \multicolumn{3}{|c|}{$G E$} & \multicolumn{3}{|c|}{$W M T$} \\
\hline & $n=0$ & $n=3$ & $n=5$ & $n=0$ & $n=3$ & $n=5$ & $n=0$ & $n=3$ & $n=5$ \\
\hline \multirow[t]{2}{*}{ Constant } & $-8.67^{* * * *}$ & $-4.5^{* * *}$ & $25.9^{* * * *}$ & $-5.5^{* * * *}$ & $-8.88^{* * * *}$ & $-22^{* * *}$ & -0.12 & -0.315 & $-4.2^{* * * *}$ \\
\hline & $(-8.09)$ & $(-10.1)$ & (12.84) & $(-13.8)$ & $(-26)$ & $(-10.6)$ & $(-0.7)$ & $(-1.52)$ & $(-4.52)$ \\
\hline \multirow[t]{2}{*}{$\mathrm{P}_{\mathrm{M}}$} & $1.74^{* * * *}$ & $1.09^{* * * *}$ & $0.88^{* * *}$ & $1.15^{* * *}$ & $1.55^{* * *}$ & $1.74^{* * * *}$ & $0.57^{* * *}$ & $0.63^{* * *}$ & $0.53^{* * *}$ \\
\hline & (11.39) & (16) & (15.9) & $(20.4)$ & (30) & $(30.5)$ & $(23.6)$ & (20) & (20.7) \\
\hline$r^{2}$ & 0.342 & 0.943 & 0.974 & 0.625 & 0.864 & 0.885 & 0.69 & 0.77 & 0.893 \\
\hline $\mathrm{N}$ & & 252 & & & 252 & & & 252 & \\
\hline Mean & & 3.545 & & & 2.639 & & & 3.858 & \\
\hline
\end{tabular}

Description: polynomial order $\mathrm{n}$ takes value of 0,3 , and $5, \mathrm{n}=0$ corresponds to the model without the chebyshev polynomial term. $\mathrm{N}$ indicates the days of estimation window.

\section{An Empirical Example}

In this section we conduct an empirical examination to illustrate the application of our proposed market model. We collect layoff announcements for the Fortune 500 companies from 1997 to 2006 . The objective of the study is to investigate how the layoff announcements impact the stocks. There are altogether 656 layoff announcements after we filter only the first layoff announcement for each fiscal year. Both daily adjusted closing price and return are collected from CRSP. Return is the daily change in the total value (denoted by Ret in CRSP) and price is the daily close adjusted for distributions (denoted by Adjprc in CRSP). The event window is $(-5,5)$, which has 11 trading days with the layoff announcement at trading day 0 (If the announcement is reported at the weekends or holidays, the next trading day will be counted as day 0 ). The estimation window includes 250 trading days, which is from trading day -256 to -6 . The step size is 0.004 , except some stocks don't have complete data in the beginning of estimation window. In such a case the step size would be $1 / \mathrm{N}$, where $\mathrm{N}$ is the number of available data in the estimation window. Since our proposed model uses the stock prices instead of the stock returns as the variables, existing software such as Eventus cannot be directly applied and we use Stata for the study instead. For each layoff event all data in the estimation window is regressed in both equation (1) and (2). Figure 1 shows the calculated coefficients of determination $\mathrm{r} 2$ of both the basic market model as in Equation (1) and the time-related market model as in Equation (2) for all 656 layoff announcements. Every blue dot represents the r2 regression result of the time-varied market model and every red dot represents the $\mathrm{r} 2$ result of the basic market model. The average $\mathrm{r} 2$ of the basic market model is 0.22 and the average $\mathrm{r} 2$ of the time-related market model is 0.83 . The large increase of $\mathrm{r} 2$ clearly indicates the improvement of the modified model.

Next, we predict the stock prices in the event window for all layoff events and calculate the abnormal returns in the event window. Previous literature examines whether the abnormal returns are different from zero. We suggest a slightly different approach. Here we also calculate the errors in the estimation window and check if the abnormal returns are statistically different from the errors in the estimation window. One reason to use this approach is the length limitation of the event window. As we discussed the extrapolation technique restricts the length of the event window. If the extrapolation range extends beyond appropriate, the accuracy may decrease sharply. With only a few data available in the event window $(-5,5)$, it would be difficult to apply appropriate statistic tools, especially when the data are not normally distributed. Also, although zero mean value of error terms is a good approximation in the estimation window, the assumption may not be accurate in the event window due to extrapolation. Thus we calculate the errors in the estimation window and compare them with the abnormal returns in the event window. The Shapiro-Wilk test is applied to assess the normality of the abnormal returns. The results show that there are only 55 
events that are statistically close to the normal distribution and the average $\mathrm{z}$ value of all events is 4.6. It suggests that most events are not normally distributed. So we use two-sample t-test on the 55 events with approximate normal distributions and Wilcoxon rank-sum nonparametric test on the other 601 events.

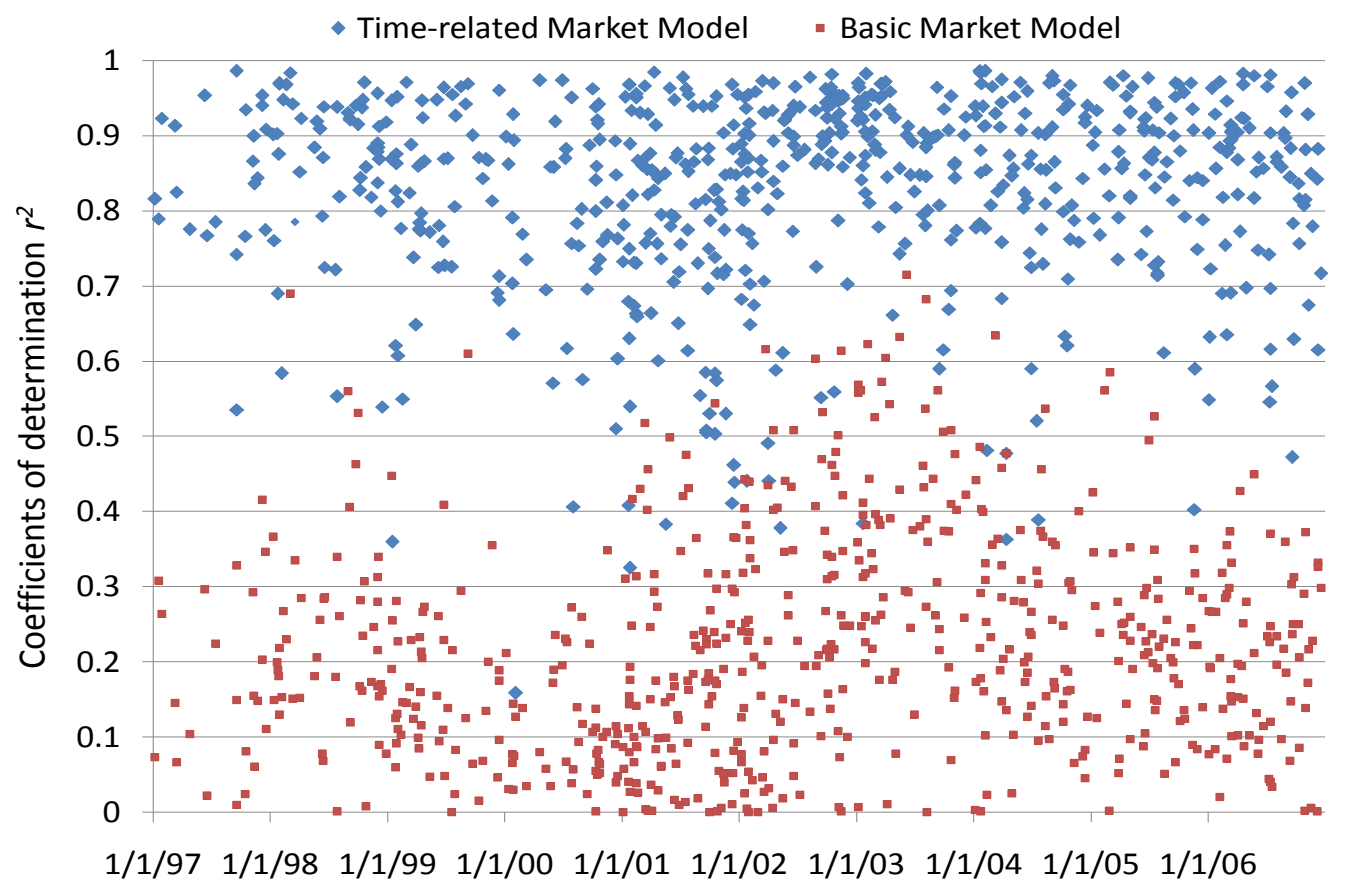

Layoff Announcement Date

Figure 1. Coefficient of determination $\mathrm{r} 2$ of the time-related market model vs. the basic market model

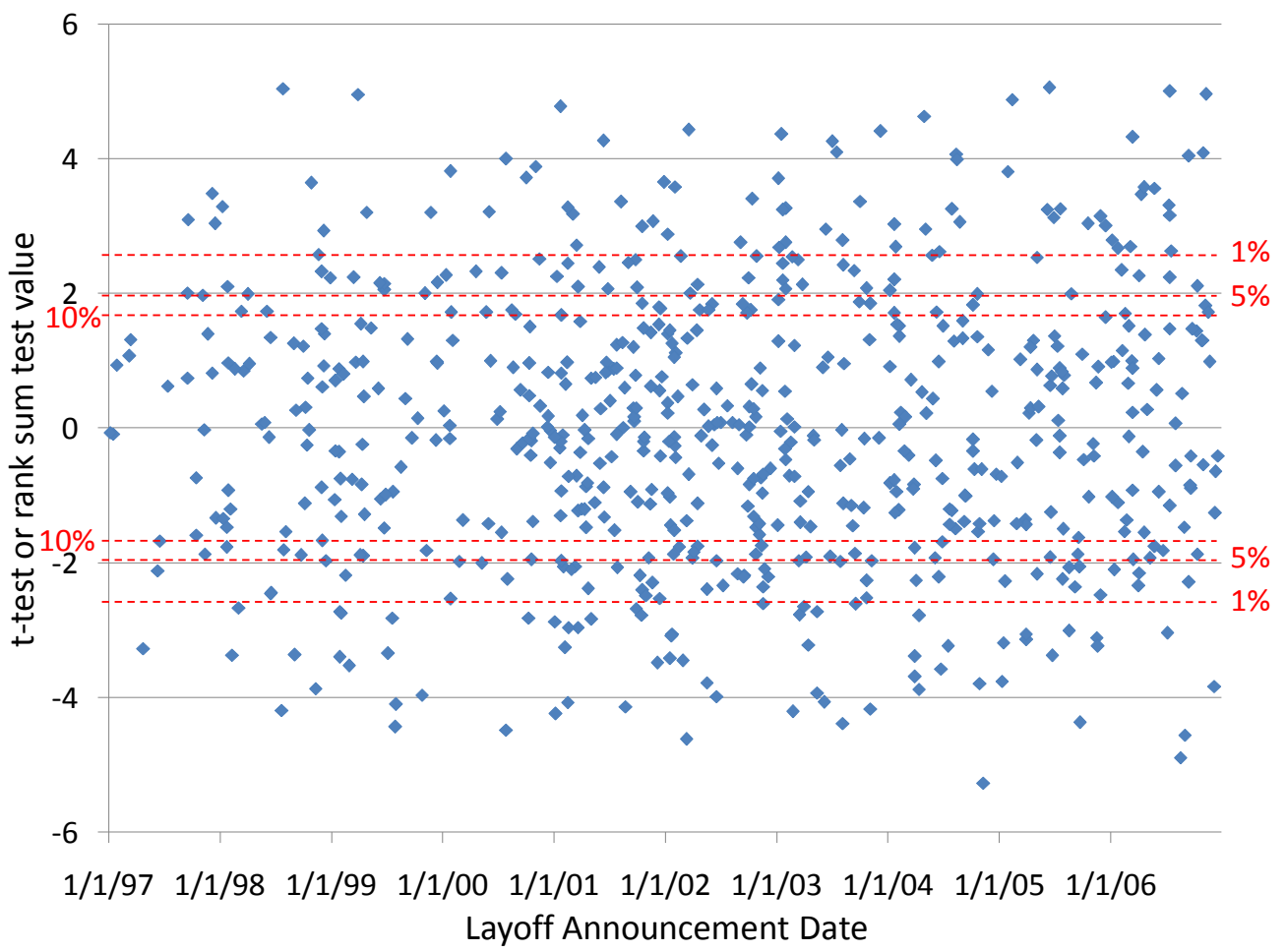

Figure 2. Calculated $t$ or $\mathrm{z}$ values of all layoff events using the modified market model 
Figure 2 shows the resultant $\mathrm{t}$ or $\mathrm{z}$ value for all events. There are 122 (or 114) events with abnormal returns significantly higher (or lower) than the errors in the estimation window with a $95 \%$ confidence level. We further calculate the cumulative abnormal returns (CAR) for all events by summarizing the abnormal returns over all trading days in the event window. The average CAR for all events is -0.15 , and the standard deviation is 3.9. The average CAR is not statistically different from zero and thus suggests there is no significant effect of the layoff announcement on the stock price in our interested time window ranged $(-5,5)$. In empirical application, our focus is not to examine the effect of layoff announcements but to empirically apply the proposed modified market model for event study. As such, we do not try to interpret and explain the results on the effect of layoff announcements.

\section{Conclusion}

In summarization, we analyze two essential assumptions in the event study: the investigated event impacts the stock mostly inside the event window and the stock behavior in the event window without the event taking place is predictable by its behavior in the estimation window. More importantly, we propose a modified market model as an improvement to the basic market model. The new model takes into account both the macro market performance and the micro individual stock behavior. We use a Chebyshev polynomial term to capture the asynchronous behavior of an individual stock from the overall market. The proposed model is very successful at increasing the model's explanatory power in terms of the coefficient of determination $\mathrm{r} 2$. We also conduct an empirical examination on both the modified market model and the original market model. We collect 656 layoff events in Fortune 500 companies from 1997 to 2006. Figure 1 shows the significant improvement of the new model using the model's $\mathrm{r} 2$ as the measure. The average $\mathrm{r} 2$ of the original market model is 0.22 and the average $\mathrm{r} 2$ of the modified market model is 0.83. The empirical example demonstrates that the proposed model may improve the explanatory power of the model to a large extent and can be applied to all event studies. In this study we do not intent to address the non-stationary property in event study. Further studies of time series analysis to evaluate the non-stationary properties would appear to offer interesting insight into the methodology of event study.

\section{References}

Agrawal, J. \& Kamakura, W. A. (1995). The economic worth of celebrity endorsers: An event study analysis. The Journal of Marketing, 59(3), 56-62. https://doi.org/10.2307/1252119

Arfken, G. B. \& Weber, H. J. (1995). Mathematical Methods for Physicists. San Diego, CA, Academic Press.

Ball, R. \& Brown, P. (1968). An empirical evaluation of accounting income numbers. Journal of Accounting Research, 6(2), 159-177. http://dx.doi.org/10.2307/2490232

Baker, M., Greenwood, R. \& Wurgler, J. (2009). Catering through nominal share prices. Journal of Finance, 64(6), 2559-2590. https://doi.org/10.1111/j.1540-6261.2009.01511.x

Barber, B. \& Lyon, J. (1997). Detecting long-run abnormal stock returns: The empirical power and specification of test statistics. Journal of Financial Economics, 43(3), 341-372. https://doi.org/10.1016/S0304-405X(96)00890-2

Barclay, M. \& Litzenberger, R. (1988). Announcement effects of new equity issues and the use of intraday price data. Journal of Financial Economics, 21(1), 71-99. https://doi.org/10.1016/0304-405X\%2888\%2990032-3

Bemard, V. L. (1987). Cross-sectional dependence and problems in inference in market based accounting research. Journal of Accounting Research, 25, 1-48. http://doi.org/10.2307/2491257

Bessembinder, W., Kahle, K. M., Maxwell, W. F. \& Xu, D. (2009). Measuring abnormal bond performance. Review of Financial Studies, 22, 4219-4258. https://doi.org/10.1093/rfs/hhn105

Bhagat, S. \& Romano, R. (2002). Event studies and the law: Part I: technique and corporate litigation. American Law and Economics Review, 4(1), 141-168. https://doi.org/10.1093/aler/4.1.141

Bhagat, S. \& Romano, R. (2002). Event studies and the law: Part II: empirical studies of corporate law. American Law and Economics Review, 4(2), 380-423. https://doi.org/10.1093/aler/4.2.380

Boehmer, E., Musumeci, J. \& Poulsen, A. B. (1991). Event study methodology under conditions of event induced variance. Journal of Financial Economics, 30, 253-272. http://doi.org/10.1016/0304-405X(91)90032-F

Boer, K., Kaymak, U. \& Spiering, J. (2006). From Discrete-Time Models to Continuous-Time, Asynchronous Models of Financial Markets. ERIM Report Series Reference No. ERS-2006-009-LIS. http://doi.org/10.1111/j.1467-8640.2007.00302.x

Brown, S. \& Warner, J. (1980). Measuring security price performance. Journal of Financial Economics, 8, 205-258. 
https://doi.org/10.1016/0304-405X\%2880\%2990002-1

Brown, S. \& Warner, J. (1985). Using daily stock returns: The case of event studies. Journal of Financial Economics, 14, 3-31. http://dx.doi.org/10.1016/0304-405X(85)90042-X

Brown, S. \& Weinstein, M. (1985). Derived factors in event studies. Journal of Financial Economics, 14, $491-495$.

Carhart, M. (1997). On persistence in mutual fund performance. Journal of Finance, 52(1), 57-82. https://doi.org/10.1111/j.1540-6261.1997.tb03808.x

Collins, D. W. \& Dent, W. T. (1984). A comparison of alternative testing methodologies used in capital market research. Journal of Accounting Research, 22 (1), 48-84.

Core, J. \& Guay, W. (1999). The use of equity grants to manage optimal equity incentive levels. Journal of Accounting and Economics, 28 (2), 151-184. http://doi.org/10.1016/S0165-4101(99)00019-1

Cowan, A. R. (1993). Tests for cumulative abnormal returns over long periods: Simulation evidence. International Review of Financial Analysis, 2(1), 51-68. https://doi.org/10.1016/1057-5219(93)90006-4

Dodd, P. \& Warner, J. B. (1983). On corporate governance: A study of proxy contests. Journal of Financial Economics, 11(1), 401-438. https://doi.org/10.1016/0304-405X(83)90018-1

Eckbo, B. E. (1983). Horizontal mergers, collusion, and stockholder wealth. Journal of Financial Economics, 11(1-4), 241-273. https://doi.org/10.1016/0304-405X(83)90013-2

Eckbo, B. E., Masulis, R. \& Norli, O. (2000). Seasoned public offerings: resolution of the "new issues puzzle." Journal of Financial Economics, 56(2), 251-291. http://dx.doi.org/10.1016/S0304-405X(00)00041-6

Fama, E. (1998). Market efficiency, long-term returns, and behavioral finance. Journal of Financial Economics, 49 (3), 283-306. http://doi.org/10.1016/S0304-405X(98)00026-9

Fama, E. F., Fisher, L., Jensen, M. C. \& Roll, R. (1969). The adjustments of stock prices to new information. International Economic Review, 10(1), 1-21. https://doi.org/10.2307/2525569

Fama, E. F. \& French, K. (1993). Common risk factors in the returns on stocks and bonds, Journal of Financial Economics, 33(1), 3-56. https://doi.org/10.1016/0304-405X(93)90023-5

Fama, E. F. \& French, K. (1996). Multifactor explanations of asset pricing anomalies, Journal of Finance, 51(1), 55-84. https://doi.org/10.1111/j.1540-6261.1996.tb05202.x

Foster, G., Olsen, C. \& Shevlin, R. (1984). Earnings releases, anomalies, and the behaviour of security returns. The Accounting Review, 59 (4), 574-603.

Froot, K. A. (1989). Consistent covariance matrix estimation with cross-sectional dependence and heteroskedasticity in financial data. Journal of Financial and Quantitative Analysis, 24(3), 333-355.

Giroud, X. \& Mueller, H. (2011). Corporate governance, product market competition, and equity prices. Journal of Finance, 6(2), 563-600. https://doi.org/10.1111/j.1540-6261.2010.01642.x

Glascock, J. L., Davidson, W. N. \& Henderson, G. V. (1987). Announcement effects of Moody's bond rating changes on equity returns. Quarterly Journal of Business and Economics, 26, 67-78.

Grinblatt, M.S., Masulis, R.W. \& Titman, S. (1984). The valuation effects of stock splits and stock dividends. Journal of Financial Economics, 13(4), 461-490. https://doi.org/10.1016/0304-405X(84)90011-4

Jaffe, J. K. (1974). Special information and insider trading. Journal of Business, 47(3), 410-428. http://dx.doi.org/10.1086/295655

Jarrell, G. A. \& Poulsen, A. (1989). The returns to acquiring firms in tender offers: evidence from three decades. Financial Management, 18(3), 12-19.

Kothari, S. \& Warner, J. (1997). Measuring long-horizon security price performance. Journal of Financial Economics, 43(3), 301-339. https://doi.org/10.1016/S0304-405X(96)00899-9

Kothari, S. \& Warner, J. (2007). Econometrics of event studies. Handbook of Corporate Finance: Empirical Corporate Finance, Vol. 1, Elsevier/North-Holland, Amsterdam.

Li, Z. F. (2014). Mutual monitoring and corporate governance. Journal of Banking \& Finance, 45, $255-269$. https://doi.org/10.1016/j.jbankfin.2013.12.008

Lintner. J. (1965). The valuation of risk assets and the selection of risky investments in stock portfolios and capital 
budgets. Review of Economics and Statistics, 47, 13-37.

Louis, H. \& Robinson, D. (2005). Do managers credibly use accruals to signal private information? Evidence from the pricing of discretionary accrual around stock splits. Journal of Accounting and Economics, 39(2), 361-380. https://doi.org/10.1016/j.jacceco.2004.07.004

Lyon, J., Barber, B. \& Tsai, C. (1999). Improved methods of tests of long-horizon abnormal stock returns. Journal of Finance, 54, 165-201. https://doi.org/10.1016/j.jacceco.2004.07.004

MacKinlay, A. C. (1997). Event studies in economics and finance. Journal of Economic Literature, 35(1), 13-39.

Malatesta, P. H. \& Thompson, R. (1985). Partially anticipated events: a model of stock price reactions with an application to corporate acquisitions. Journal of Financial Economics, 14(2), 237-250. https://doi.org/10.1016/0304-405X(85)90016-9

Mandelker, G. (1974). Risk and return: the case of merging firms. Journal of Financial Economics, 1(4), 303-335. https://doi.org/10.1016/0304-405X(74)90012-9

McNichols, M. \& Dravid, A. (1990) Stock dividends, stock splits, and signaling. Journal of Finance, 43(3), 857-879. https://doi.org/10.1111/j.1540-6261.1990.tb05109.X

Mikkelson, W. H. \& Partch, M. M. (1986). Valuation effects of security offerings and issuance process, Journal of Financial Economics, 15, 31-60

Mitchell, M. \& Netter, J. (1994). The role of financial economics in securities fraud cases: applications at the SEC, Business Lawyer, 49, 545-590.

Mitchell, M. \& Stafford, E. (2000). Managerial decisions and long-term stock price performance. Journal of Business, 73, 287-329. http://dx.doi.org/10.2139/ssrn.94137

Patell, J. (1976). Corporate forecasts of earnings per share and stock price behavior empirical tests. Journal of Accounting Research, 14, 246-276.

Press, W. H., Teukolsky, S. A., Vetterling, W. T. \& Flannery, B. P. (1992). Numerical Recipes in Fortran. New York: Cambridge University Press.

Ritter, J. R. (1991). The long-run performance of initial public offerings. Journal of Finance, 46(1), 3-27. https://doi.org/10.1111/j.1540-6261.1991.tb03743.x

Ross, S. (1976). The arbitrage theory of capital asset pricing. Journal of Economic Theory, 13, 341-360. https://doi.org/10.1016/0022-0531(76)90046-6

Salinger, M. (1992). Standard errors in event studies. Journal of Financial and Quantitative Analysis, 27(1), 39-53. https://doi.org/10.2307/2331297

Schwert, G. W. (1981). Using financial data to measure effects of regulation. Journal of Law and Economics, 24(1), 121-158. https://doi.org/10.1086/466977

Sharp. W. F. (1964). Capital asset prices: a theory of market equilibrium under conditions of risk, Journal of Finance, 19, 425-442. https://doi.org/10.1111/j.1540-6261.1964.tb02865.x

Sweeney. R. J. (1991). Levels of significance in event studies. Review of Quantitative Finance and Accounting, 1(4), 373-382.

White, H. (1980). A heteroskedasticity-Consistent Covariance Matrix Estimator and a direct test for heteroskedasticity. Econometrica, 48(4), 817-838. 


\section{Appendix}

The transformation of the market model with the stock price as the variable to the market model with the stock return as the variable as follows:

$$
\begin{aligned}
\ln P_{i t} & =\alpha_{i}+\beta_{i} \times \ln P_{M t}+\epsilon_{i t} \\
\ln P_{i(t-1)} & =\alpha_{i}+\beta_{i} \times \ln P_{M(t-1)}+\epsilon_{i(t-1)}
\end{aligned}
$$

Subtract the two equations and we get

$$
\ln \frac{P_{i t}}{P_{i(t-1)}}=\beta_{i} \times \ln \frac{P_{M t}}{P_{M(t-1)}}+\epsilon_{i t}-\epsilon_{i(t-1)}
$$

Use the exponential function on both sides, we obtain

$$
\frac{P_{i t}-P_{i(t-1)}}{P_{i(t-1)}}+1=e^{\epsilon_{i t}-\epsilon_{i(t-1)}} \times\left(\frac{P_{M t}-P_{M(t-1)}}{P_{M(t-1)}}+1\right)^{\beta_{i}}
$$

Replaced price with return, we have

$$
R_{i t}=e^{\epsilon_{i t}-\epsilon_{i(t-1)}} \times\left(R_{M t}+1\right)^{\beta_{i}}-1
$$

Since in most cases daily market return $M R_{t} \ll 1$

$$
R_{i t}=\beta_{i} \times e^{\epsilon_{i t}-\epsilon_{i(t-1)}} \times R_{M t}+e^{\epsilon_{i t}-\epsilon_{i(t-1)}}-1
$$

Thus, the market model using the stock price as the variable may be transformed to the market model using the stock return as the variable. 